\title{
Pregnancy-Related Acute Myocardial Infarction: A Review of Epidemiology, Diagnosis, Medical and Surgical Management
}

\author{
Mohammad Reza Taban Sadeghi ${ }^{1}$, Naser Aslanabadi², Naser Khezerlou Aghdam ${ }^{1}$, Razieh Parizad ${ }^{3}$, Hossein \\ Namdar ${ }^{*}$
}

\begin{abstract}
Although acute myocardial infarction (AMI) in pregnancy is rare, can result in maternal and/or fetal death and should be carefully managed. The aim of this study is to collect and review the data on the management from numerous articles published since 2000. For literature review we performed a literature search on PubMed that were based on diagnoses and management of myocardial infarction on pregnancy. Atherosclerosis appears to be the most common cause of AMI. Although there are some differences related to pregnancy stage such as thrombosis, coronary artery spasm or dissection that seen more frequently in pregnant women than agematched nonpregnant women. In addition to traditional risk factors of atherosclerosis in general population, some other risk factors due to physiological or pathological changes in pregnancy and also some drugs can cause AMI. The Presentation and diagnosis of AMI in pregnancy usually is the same as nonpregnant patients but there are some important points. Regardless of some differences, therapeutic option of AMI in pregnant women is the same of nonpregnant patients. Probably primary percutaneous coronary intervention is the optimal medical management of AMI during pregnancy. Use of thrombolytic therapy in pregnancy is prohibited and is very limited. Although there have been many reports of cardiopulmonary bypass surgery during pregnancy, most knowledge is based on anecdotal and old reports. Early detection and multidisciplinary approach and timely delivery can minimize the serious consequences of AMI in pregnancy.
\end{abstract}

Keywords: Myocardial Infarction, Pregnancy, Diagnosis, Management

\section{Introduction}

The prevalence of cardiac disease in pregnancy is about $0.4-4 \%$ based on various study (1-3). Although heart disease and thromboembolism are one of the leading causes (about 32\%) of maternal death in pregnancy (4), ischemic heart disease (IHD) and myocardial infarction (MI) are uncommon in pregnancy with a rate less than $1 / 10000$ deliveries in western countries (4-9). Studies showed that pregnancy increases the risk of acute myocardial infarction (AMI) up to 3-4 fold compared with nonpregnant reproductive-age women $(2,4,5,10)$ and have poor maternal and fetal outcome (10-12). Maternal mortality rate is about $5-37 \%$ and is twice higher with AMI in peripartum in comparison with mortality in antepartum and postpartum $(11,12)$. Fetal mortality is mainly associated with maternal mortality and is about 9-34\%. Maternal survival is associated with good fetal prognosis (12). The aim of this study is to collect and review the new data on the diagnosis and management of acute $\mathrm{MI}$ in pregnancy from numerous articles published since 2000 .

Materials and Methods
For literature review we performed a literature search in
Medline/Pub Med electronic database in the internet for original articles on this topic since 2000. our key words was " myocardial infarction", "pregnancy", "diagnosis", and "management". In some issue if there was not new study, we looked older studies too.

\section{Results and Discussion}

There is no epidemiological study about pregnancy related AMI in Iran, but the incidence may be lower in Iran as in other Asian study (13). AMI has traditionally been considered a disease affecting mostly men, yet women are increasingly at risk and some previous studies showed a delay in the diagnosis of AMI and an increase risk of death of the women, but in a new study in Iran, there were no difference in admission, indication for coronary angiography (CAG) and death compared with men (14). AMI in pregnancy is reported ranging from 19-44 years, but the incidence is higher after 30 years of age with odds ratio of 6-7 (5) and the peak incidence of AMI reported in multigravida older than 33 year of age (11) and most commonly occur during 3 th trimester or peripartum(9). If AMI occur during delivery or within two weeks of labor, mortality may be as high as $45 \%$ of patients $(9,11)$. Most patient presenting with AMI in post partum period are

Received 2 May 2014, Revised 17 May 2014, Accepted 13 June 2014, Available online 20 July 2014

${ }^{1}$ Assistant Professor, Cardiovascular Research Center, Tabriz University of Medical Sciences, Tabriz, Iran. ${ }^{2}$ Associate Professor, Cardiovascular Research Center, Tabriz University of Medical Sciences, Tabriz, Iran. ${ }^{3}$ BSc, Cardiovascular Research Center, Tabriz University of Medical Sciences, Tabriz, Iran.

*Corresponding Author: Hossein Namdar, Assistant Professor, Cardiovascular Research Center, Tabriz University of Medical Sciences, Tabriz, Iran. Email: namdar.hn@gmail.com 
younger than patient presenting with AMI in antepartum or peripartum periods (15). Traditional risk factors of atherosclerosis in general population are related with increased risk of pregnancy related AMI (8).

The pathophysiology of AMI in pregnancy is the same as nonpregnant patients, although there are some differences related to pregnancy stage such as thrombosis, coronary artery spasm or dissection that are more frequent in pregnant women than aged matched nonpregnant women $(16,17)$. Rupture of atherosclerotic plaque is the most common cause of AMI in pregnant patients especially in antepartum period (17). Coronary artery dissection is an important cause of MI with a rate of $50 \%$ in peripartum period $(11,18,19)$.

Some physiological changes during normal pregnancy and also some pathological events during complicated pregnancy and some drugs can cause AMI or worse the prognosis of AMI in pregnancy $(10,20)$. The normal hemodynamic changes in pregnancy such as increased heart rate and cardiac output, physiological anemia, increased stress, anxiety, pain, uterine contraction and blood loss during delivery that can increase oxygen demand during artery spasm can reduce coronary supply $(10,11)$. Underlying causes include enhanced vascular response to angiotensin II and noradrenalin and reduce response to vasodilators (endothelial dysfunction) in gestational hypertension and preeclampsia, increased rennin level in response to uterine hypoperfusion in supine position (21). Also some drugs such as administration of Ergotamine to control of hemorrhage or use of Bromocriptine to suppress lactation can induced coronary artery spasm and reduce coronary supply in peripartum and postpartum period (22-26).

Normal pregnancy is a hypercoagulable state due to decreased protein $S$ level and tissue Plasminogen Activator (tPA) level specially during placenta separation, so thromboembolic events increase during pregnancy and labor and rarely coronary thrombosis is a course of AMI in pregnancy $(27,28)$.

Clinical Presentation and Diagnosis: Presentation of AMI in pregnancy usually is the same as nonpregnant patients with typical anginal chest pain, ST-T changes and Q wave in electrocardiography (ECG) and elevated cardiac enzymes, but several important points must be noted (17). Normal pregnancy can mimic some of cardiac disease symptoms, making it difficult to diagnose of true cardiac disease. For example, dizziness, fatigue, dyspnea, palpitation, tachypnea or tachycardia, pedal edema, decreased exercise tolerance and even syncope may be seen in normal pregnancy due to physiological changes. Also some of cardiac signs can be found in normal pregnant patients such as elevated jugular vein pressure, apical point displacement, parasternal lift, increase S1 or S2 heart sounds and even extra heart sounds such as S3 or systolic ejection murmur (17). During normal pregnancy creatine kinase $(\mathrm{CK})$ concentration can increase and then specificity of CK-MB is lower $(29,30)$. Cardiac specific troponin I (cTnI) is more specific than CK-MB, because cTnI level does not increase above normal limit during uncomplicated pregnancy, delivery, or surgical cesarean section (CS) but can be elevated in gestational hypertension or preeclampsia (29-31).

ECG changes in pregnancy associated AMI is the same as nonpregnant patients, but some pregnancy-related changes can be seen in normal uncomplicated women such as left axis deviation due to diaphragmatic elevation by fetus or Q wave and T inversion in lead III $(8,17,32)$. Also in pregnant patients, CAG can be helpful in diagnosis of AMI, but radiation exposure is the main concern and CAG have to be used in the definite AMI for therapeutic means by primary percutaneous coronary intervention (PCI) (18,33-35). By using of the abdominal shield, fetal radiation exposure will be less than one rad and termination of pregnancy is not necessary until radiation exposure exceeds 10 rads $(36,37)$.

In one study, coronary artery morphology of acute MI in pregnancy was reported as atherosclerotic plaque rupture in only about $43 \%$, coronary thrombosis about $21 \%$, dissection $16 \%$ and spasm in $1 \%$. Normal CAG may be seen in $29 \%$ of patient with several explanations such as repeated coronary dissection, vasospasm or clot autolysis (10). The important differential diagnosis of chest pain in pregnant women is hemorrhage, sickle cell anemia crisis, preeclampsia, pulmonary embolism and aortic dissection (10).

Treatment (Medical and Surgical Management): Regardless of some minor differences, therapeutic option of AMI in pregnant women is the same of nonpregnant patients. Recommended pharmacological therapies are beta blockers, heparin or enoxaparin, ASA, nitrates, clopidogrel. If necessary, non dihydropyridine calcium channel blockers may be used (38-41). Angiotensin receptor blockers and angiotensin convertase enzyme inhibitors are contraindicated after first trimester, but they are not major teratogens when used in the first trimester $(42,43)$. Statins should be avoided, because their safety have not been proved (44). Among beta blockers, labetalol and metoprolol have lower teratogenicity and are safer than others (45). Nitrates are safe in pregnancy but dosage should be carefully titrated to avoid maternal hypotension and consequent uterine hypoperfusion (46). Unfractionated heparin (UFC) and low molecular heparin (LMWH) are safe in pregnancy but anticoagulation should be discontinued 12-24 hours before induction of labor $(47,48)$. Antiplatelet therapy is essential in AMI. Also use of ASA in first trimester is associated with fetal defects, but low dose ASA is safe in $2^{\text {nd }}$ and $3^{\text {th }}$ trimester $(49,50)$ and breastfeeding (51). Safety of thienopyridines such as clopidogrel is not clearly defined during pregnancy but breastfeeding is not recommended in this patients (52). Among calcium channel blockers, nifedipine may be safe but data about the other nondihydropyridines are limited. Diltiazem and Verapamil are prohibited in pregnancy and breastfeeding (51-53).

Revascularization is principle of treatment in AMI in pregnant women As others nonpregnant patients (17). 
Primary PCI or coronary artery bypass graft (CABG) and rarely thrombolysis has been performed successfully during pregnancy and may be the best therapeutic option in pregnancy. In most clinical trials, pregnant women have been excluded and there is little data about efficacy and safety of primary PCI in pregnant women with AMI (54-56). Main concern in primary PCI is radiation and need to dual antiplatelet therapy at least for one month after bare metal stents (BMS) or 12 months after drug eluted stents (DES) use, and for this reason BMS is preferred during pregnancy (57-59). In dual antiplatelet therapy period, epidural anesthesia for labor is contraindicated (60).

Experience in thrombolytic therapy for AMI in pregnancy is limited. Some time it may be considered when primary PCI is not available. Streptokinase is prohibited during pregnancy $(61,62)$ but thrombolysis with tPA, is theoretically possible. The large molecular weight of tPA makes it impossible to cross the placenta, but there is an increased risk of catastrophic hemorrhage $(63,64)$.

CABG: Although successful CABG in pregnant women has been reported before 1960, over time, significant technical improvement has been caused improvement in maternal and fetal outcomes. Based on recent studies, the maternal mortality is about 1.7 to $3 \%$, as the same of non pregnant women.

Fetal mortality is based on time of surgery and several technical consideration such as left lateral recumbent positioning of mother in gestational age after $20^{\text {th }}$ week to reduce aortic and caval compression, preserving maternal mean arterial blood pressure about $70 \mathrm{mmHg}$ or more throughout surgery and as possible, normothermic or mild hypothermic condition and high flow extra corporeal circulation and also monitoring of fetal heart rate and prevention of fetal bradycardia to preserve fetoplacental circulation.

The best surgical time to CABG in pregnant women is early second trimester. In first trimester there is increased chance of fetal malformation and in late second and early third trimester there is increased chance of preterm labor. After 28 weeks of gestational age, immediately after CS, cardiac surgery can be done (65-69).

Delivery: The method of delivery is based on obstetrical indications and patients clinical status (17). If it is possible, the best way to reduce the risk of delivery is postponed about 2-3 weeks after AMI $(10,17)$. There is no clear advantage in terms of mortality between CS or vaginal delivery. CS has risk of anesthesia, surgical induced hemodynamic changes, more bleeding and reduction in hemoglobin and more risk of respiratory complications such as infections $(10,17)$. But On the other hand, in vaginal delivery, there is more sympathetic release due to labor pain and hemodynamic changes that can lead to inducing or worsening of ischemia (11).

Positioning the patient in left lateral position can reduces aortorenal compression and therefore optimizes cardiac output and placental perfusion (17). Assistance and shortening of the $2^{\text {nd }}$ stage of labor can reduce maternal cardiac strain. Limited pushing is eligible if there are no heart failure signs and ejection fraction is over $40 \%$ (17). Oxytocin infusion should be avoided to prevent coronary spasm and heart ischemia. Monitoring of heart rate, blood pressure, ECG, and monitoring of rhythm, pulse oximetry, and sometimes arterial line or swan-ganz catheter if necessary, and also use of routine drugs in acute cardiac ischemia such as beta blockers, nitroglycerines, antihypertension medications and supplementary oxygen during labor will be eligible. With adequate attention and medication, good controlling of pain and reducing 2nd stage of delivery, most patients with AMI can tolerate vaginal delivery with acceptable risk, but sometimes CS is necessary in hemodynamically unstable patients $(17,60)$. After pregnancy, the patient should be followed closely by cardiologist to adjust physical activity and review cardiac symptoms. History of MI is not absolute contraindication of pregnancy but patient should be advised to delay pregnancy about one year after complete treatment of remnant ischemia and revascularization (70).

\section{Conclusions}

Although MI is uncommon in pregnancy but pregnancy increases the risk of AMI up to 3-4 fold and increase risk of maternal and fetal mortality.

Early detection and multidisciplinary approach and timely delivery can minimize the serious consequences of AMI in pregnancy. There is some differences in medication of AMI in pregnant patient compared with nonpregnant patients such as limitation of thrombolytic therapy or use of Angiotensin receptor blockers, angiotensin convertase inhibitors and statins. CABG is possible in early second trimester in pregnant patients.

\section{Ethical issues}

The local ethics committee approved the study.

\section{Conflict of interests}

Authors declare that they have no conflict of interests.

\section{Acknowledgments}

We would like to thank all of our colleagues who helped us in this study.

\section{References}

1. McFaul PB, Dornan JC, Lamki H, Boyle D. Pregnancy complicated by maternal heart disease. A review of 519 women. Br J Obstet Gynaecol 1988;95:861-7.

2. Badui E, Enciso R. Acute myocardial infarction during pregnancy and puerperium: a review. Angiology 1996;47:739-56.

3. Tan J, de Swiet M. Prevalence of heart disease diagnosed de novo in pregnancy in a West London population. Br J Obstet Gynaecol 1998;105:1185-8.

4. Ladner HE, Danielson B, Gilbert WM. Acute myocardial infarction in pregnancy and the puerperium: a population-based study. Obstet Gynaecol 2005;105:480-4. 
5. James AH, Jamison MG, Biswas MS, Brancazio LR, Swamy GK. Myers ER. Acute myocardial infarction in pregnancy: a United States population-based study. Circulation 2006;113:1564-71.

6. Kealey AJ. Coronary artery disease and myocardial infarction in pregnancy: A review of epidemiology, diagnosis, and medical and surgical management. Can J Cardiol 2010; 26: 185 -189.

7. Bush N, Nelson-Piercy C, Spark P, Kurinczuk JJ, Brocklehurst P, Knight M. Myocardial infarction in pregnancy and postpartum in the UK. Eur J Cardiovasc Prev Rehabil 2011; 18: 810-2.

8. Ray P, Murphy GJ, Shutt LE. Recognition and management of maternal cardiac disease in pregnancy. Br J Anaesth 2004; 93 (3): 428-39

9. Hankins GDV, Wendel GD, Leveno KJ, Stoneham J. Myocardial infarction during pregnancy: a review. Obstet Gynecol 1985; 65: 139-46

10. Roth A, Elkayam U. Acute myocardial infarction associated with pregnancy 1996; 125: 751 - 762.

11. Roth A, Elkayam U. Acute myocardial infarction associated with pregnancy. J Am CollCardiol 2008; 52: 171-80.

12. Hankins GD, Wendel GD Jr, Leveno KJ, Stoneham J. Myocardial infarction during pregnancy: A review. Obstet Gynecol 1985;65:139-46.

13. Satoh H, Sano M, Suwa K, Saotome M, Urushida T, Katoh $\mathrm{H}$, et al. Pregnancy-Related Acute Myocardial Infarction in Japan - A Review of Epidemiology, Etiology and Treatment From Case Reports. Circulation 2013;77:725-33.

14. Asghari E, TabanSadeghi MR, Parizad R, Mohammasdijhale N. Management of Acute Myocardial Infarction and its Effect on Women's Health (Female Versus Male). Int J Women's Health Reproduction Sci 2014;2(3):205-213.

15. Fayomi O, Nazar R. Acute myocardial infarction in pregnancy: a case report and subject review. Emerg Med J 2007; 24:800-1.

16. Iadanza A, Del Pasqua A, Barbati R, Carrera A, Gentilini R, Favilli R, et al. Acute ST elevation myocardial infarction in pregnancy due to coronary vasospasm: A case report and review of the literature. Int J Card 2007;115:81-5.

17. Poh CL, Lee CH. Acute Myocardial Infarction in Pregnant Women. Ann Acad Med Singapore 2010;39(3):247-53.

18. Rosa GM, Bauckneht M, Ferrero S, Leone Roberti Maggiore U, Brunelli C. [Acute myocardial infarction in pregnancy]. G Ital Cardiol (Rome). 2013;14(2):126-34.

19. Emori T, Goto Y, Maeda T, Chiba Y, Haze K. Multiple coronary artery dissections diagnosed in vivo in a pregnant woman. Chest 1993; 104: 289-90.

20. Jaiswal A, Rashid M, Balek M, Park C. Acute myocardial infarction during pregnancy: A clinical checkmate. Indian Heart J 2013;65(4):464-8.

21. Sonel A, Erol C, Oral D, Omurlu K, Akyol T,
Kaymakcalan S. Acute myocardial infarction and normal coronary arteries in a pregnant woman. Cardiology 1988;75:218-20.

22. Mousa HA, McKinley CA, Thong J. Acute postpartum myocardial infarction after ergometrine administration in a woman with familial hypercholesterolaemia. Br J Obstet Gynaecol 2000; 107: 939-40

23. Sutaria N, O’Toole L, Northridge D. Postpartum acute MI follow- ing routine ergometrine administration treated successfully by primary PTCA. Heart 2000; 83: 97-8.

24. Hayashi Y, Ibe T, Kawato H, Futamura N, Koyabu S, Ikea U, et al. Postpartum acute myocardial infarction induced by ergonovine administration. Intern Med 2003;42(10):983-6.

25. Tsui BC, Stewart B, Fitzmaurice A, Williams R. Cardiac arrest and myocardial infarction induced by postpartum intravenous ergonovine administration. Anesthesiology 2001;94:363-4.

26. Iffy L, TenHove W, Frisoli G. Acute myocardial infarction in the pueriperium in patients receiving bromocriptine. Am J Obstet Gynecol 1986;155:371-2.

27. Yoshimura T, Ito $M$, Nakamura T, Okamura $H$. The influence of labor on thrombotic and fibrinolytic systems.Eur J Obstet Gynaecol Reprod Biol 1992; 44: 195-9.

28. Nelson SM, Greer IA. Thromboembolic events in pregnancy: pharmacological prophylaxis and treatment. Expert Opin Pharmacother 2007;8(17):2917-31.

29. Shivvers SA, Wians FH, Keffer JH, Ramin SM. Maternal cardiac troponin I levels during normal labor and delivery. Am J Obstet Gynecol 1999; 180: 122-7.

30. Kumagai K, Ohnaka H, Okamoto F, Yasuda M, Kamegai H, Ohmichi M. Early diagnosis of postpartum acute myocardial infarction with combined use of troponin $\mathrm{T}$ and heart-type fatty acid-binding protein rapid assay. J Obstet Gynaecol Res 2011; 37: 1484-8.

31. Sheik AU, Harper MA. Myocardial infarction during pregnancy: management and outcome of two pregnancies. Am J Obstet Gynecol 1993;169:279-84.

32. Moran C, Ni Bhuinnedin M, Geary M, Cunningham S, McKenna P, Gardiner J. Myocardial ischemia in normal patients undergoing elective cesarean section: a peripartum assessment. Anaesthesia 2001;56:1051-8.

33. Balmain S, McCullough CT, Love C, Hughes R, Heidemann B, Bloomfield P. Acute myocardial infarction during pregnancy successfully treated with primary percutaneous coronary intervention. Int J Cardiol 2007;116(3):85-7.

34. Bithell JF, Stewart AM. Pre-natal radiation and childhood malignancy: a review of British data from the Oxford survey. Br J Cancer 1975;31: 271-87.

35. Brent RL. The effect of embryonic and fetal exposure 
to X-ray,microwaves, and ultrasound: counseling the pregnant and nonpregnant patients about these risks. Semin Oncol 1989;16:347-68.

36. Chandra V, Dorsey C, Reed AB, Shaw P, Banghart D, Zhou W. Monitoring of fetal radiation exposure during pregnancy.J Vasc Surg 2013;58(3):710-4.

37. Johnson LW, Moore RJ, Balter S. Review of radiation safety in the cardiac catheterization laboratory. Cathet Cardiovasc Diagn 1992; 25: 186-94.

38. Wilson AM, Boyle AJ, Fox P. Management of ischaemic heart dis- ease in women of child-bearing age. Intern Med J 2004; 34: 694-7.

39. Qasqas SA, McPherson C, Frishman WH, Elkayam U. Cardiovascular pharmacotheraputic considerations during pregnancy and lactation. Part 2. Cardiol Rev 2004;12:240-61.

40. Weber-Schoendorfer C, Hannemann D, Meister R, Eléfant E, Cuppers-Maarschalkerweerd B, Arnon J, et al. The safety of calcium channel blockers during pregnancy: a prospective, multicenter, observational study. Reprod Toxicol. 2008;26(1):24-30.

41. Anderson JL, Adams CD, Antman EM, Bridges CR, Califf RM, Casey DE Jr, et al. ACC/AHA 2007 guidelines for the management of patients with unstable angina/non-ST-elevation myocardial infarction: a report of the American College of Cardiology/American Heart Association Task Force on Practice Guidelines (Writing Committee to Revise the 2002 guidelines for the Management of Patients with Unstable Angina/Non-ST-Elevation Myocardial Infarction) developed in collaboration with the American College of Emergency Physicians, the Society for Cardiovascular Angiography and Interventions, and the Society of Thoracic Surgeons endorsed by the American Associations of Cardiovascular and Pulmonary Rehabilitation and the Society for Academic Emergency Medicine. J Am Coll Cardiol 2007;50:1-157.

42. Diav-Citrin O, Shechtman S, Halberstadt Y, FinkelPekarsky V, Wajnberg R, Arnon J, et al. Pregnancy outcome after in utero exposure to angiotensin converting enzyme inhibitors or angiotensin receptor blockers. Reprod Toxicol 2011;31(4):540-5.

43. Enzensberger C, Eskef K, Schwarze A, Faas D, AxtFliedner R. Course and outcome of pregnancy after maternal exposure to angiotensin-II-receptor blockers--case report and review of the literature. Ultraschall Med 2012;33(5):493-6.

44. Edison RJ, Muenke M. Central nervous system and limb anomalies in case reports of first-trimester statin exposure. N Engl J Med 2004; 350: 1579-82.

45. Ersbll A, Hedegaard M, Sondergaard L, Ersboll M, Johansen M. Treatment with oral beta-blockers during pregnancy complicated by maternal heart disease increases the risk of fetal growth restriction. BJOG 2014;121(5):618-26.

46. Bullarbo M, Tjumum J, Ekerhovd E. Sublingual nitroglycerin for management of retained placenta.
Int J Gynaecol Obstet 2005;91:228-32.

47. Bates SM, Greer IA, Hirsh J, Ginsberg JS. Use of antithrombotic agents during pregnancy: the Seventh ACCP Conference on Antithrombotic and Thrombolytic Therapy. Chest 2004;126:627-44.

48. Oran B, Lee-Parritz A, Ansell J. Low molecular weight heparin for the prophylaxis of thromboembolism in women with prosthetic mechanical heart valves during pregnancy. Thromb Haemost 2004;92:747-51.

49. CLASP. A randomised trial of low-dose aspirin for the prevention and treatment of pre-eclampsia among 9364 pregnant women. CLASP (Collaborative Low-dose Aspirin Study in Pregnancy) Collaborative Group. Lancet 1994;343:619-29.

50. Imperiale TF, Petrulis AS. A meta-analysis of lowdose aspirin for the prevention of pregnancy-induced hypertensive disease. JAMA 1991;266:260-4.

51. Uzan S, Merviel P, Beaufils M, Bréart G, SalatBaroux J. Aspirin during pregnancy. Indications and modalities of prescription after the publication of the later trials. Presse Med 1996;25(1):31-6.

52. Klinzing P, Markert UR, Liesaus K, Peiker G. Case report: Successful pregnancy and delivery after myocardial infarction and essential thrombocythemia treated with clopidogrel. Clin Exp Obstet Gyn 2001;28:215-6.

53. Oei SG, Oei SK, Brolmann HA. Myocardial infarction during nife- dipine therapy for preterm labor N Engl J Med 1999;340(2):154.

54. Arimura T, Mitsutake R, Miura S, Nishikawa H, Kawamura A, Saku K. Acute myocardial infarction associated with pregnancy success- fully treated with percutaneous coronary intervention. Intern Med 2009; 48: 1383-6.

55. Mahon NG, Maree A, McKenna P, McCann HA, Sugrue DD. Emergency coronary angioplasty and stenting following acute myocardial infarction during pregnancy. J Inv Card 1999;11:233-6.

56. Eickman FM. Acute coronary artery angioplasty during pregnancy. Cath Card Diag 1996;38:369-72.

57. Sebastian C, Scherlag M, Kugelmass A, Schechter E. Primary stent implantation for acute myocardial infarction during pregnancy: Use of abciximab, ticlopidine, and aspirin. Cath Card Diag 1998;45:275-9.

58. Cuthill JA, Young S, Greer IA, Oldroyd K. Anesthetic considerations in a parturient with critical coronary artery disease and a drug-eluting stent presenting for Caesarean section. Int J Obstet Anesth 2005;14:16771.

59. Reizig K, Diar N, Walcker JL. [Myocardial infarction, pregnancy and anesthesia]. Ann Fr Anesth Reanim 2000;19:544-8.

60. Hands ME, Johnson MD, Salzman DH, Rutherford JD. The cardiac, obstetric and anesthetic management of pregnancy complicated by acute myocardial infarction. J Clin Anesth 1990;2:258-68.

61. Turrentine MA, Braems G, Eamirez MM. Use of 
thrombolytics for the treatment of thromboembolic disease during pregnancy. Obstet Gynecol Surv 1995;50:534-41.

62. Leonhardt G, Gaul C, Nietsch HH, Buerke M, Schleussner E. Thrombolytic therapy in pregnancy. J Thromb Thrombolysis 2006;21:271-6.

63. Lecander I, Nilsson IM, Astedt B. Depression of plasminogen activator activity during pregnancy by the placental inhibitor PAI 2. Fibrinolysis 1988;2:165-7.

64. Schumacher B, Belfort MA, Card RJ. Sucessful treatment of actue myocardial infarction during pregnancy with tissue plasminogen activator. Am J Obstet Gynecol 1997;176:716-9.

65. Garry D, Leikin E, Fleisher AG, Tejani N. Acute myocardial infarction in pregnancy with subsequent medical and surgical management. Obstet Gynecol 1996;87:802-4.
66. Chambers CE, Clark SL. Cardiac surgery during pregnancy. Clin Obstet Gynecol 1994;37:316-23.

67. Weiss BM, von Segesser LK, Alon E, Seifert B, Turina MI. Outcome of cardiovascular surgery and pregnancy: A systemic review of the period 19841996. Am J Obstet Gynecol 1998;179:1643-53.

68. Dufour P, Berard J, Vinatier D, Subtil D, Guionet $\mathrm{B}$, Bourzoufi $\mathrm{K}$, et al. Pregnancy after myocardial infarction and a coronary artery bypass graft. Arch Gynecol Obstet 1997;259(4):209-13.

69. Silberman S, Fink D, Berko RS, Mendzelevski B, Bitran D. Coronary artery bypass surgery during pregnancy. Eur J Cardiothorac Surg 1996;10(10):925-6.

70. Chestnut DH, Zlatnik FJ, Pitkin RM, Varner MW. Pregnancy in a patient with a history of myocardial infarction and coronary artery bypass grafting. Am J Obstet Gynecol 1986;155(2):372-3.

Copyright $(2014$ The Author(s); This is an open-access article distributed under the terms of the Creative Commons Attribution License (http://creativecommons.org/licenses/by/4.0), which permits unrestricted use, distribution, and reproduction in any medium, provided the original work is properly cited. 